\title{
PROBLEM BASED LEARNING IN BASIC MEDICAL SCIENCE TRAINING FOR 200 LEVEL PHYSIOTHERAPY STUDENTS: STUDENTS' ASSESSMENT IN THE FIRST YEAR.
}

\author{
Journal website at; \\ http://mrtbjournal.org/index.php/njmr/issue/current/showToc
}

\author{
AI Aiyegbusi, OO Olabiyi, FIO Duru ,CC Noronha, AO Okanlawon \\ Department of Anatomy, College of Medicine University of Lagos
}

Correspondence to:

FIO Duru

Dept. of Anatomy

College of Medicine, University of Lagos

PMB 12003, Lagos.

\section{SUMMARY}

Background: Problem Based learning (PBL) is increasingly becoming popular worldwide. The Department of Anatomy at the College of Medicine University of Lagos recently introduced the problem based learning approach as the style of teaching physiotherapy students in their basic medical science year.

Objective: This survey investigated the students' view of the programme, its impact on their learning as well as constraining factors.

Methods: A questionnaire-based survey was conducted at the end of the basic science academic year. The sample was the whole of a group of physiotherapy student that went through the PBL programme of the Department for one year. Results were collated and data processed using computer Microsoft excel in windows office 2003 software.

Results: A statistically significant proportion of the group rated the programme favorably and indicated it was of benefit to their learning experience. Identified areas of their learning positively impacted on include; increase in amount of knowledge ( $81 \%)$, better levels of interaction among colleagues (69\%), improved literary research and problem solving skills ( $72 \%)$, higher level of confidence $(81 \%)$ and an increased eagerness for clinical school (95\%).

Conclusion: Problem Based Learning programme can be beneficial to pioneer physiotherapy students in basic medical science year even when it is administered newly by a Department that is still developing in the programme.

Key Words: Problem Based Learning, Physiotherapy Students, Anatomy.

\section{INTRODUCTION}

Problem-based learning (PBL) has become an increasingly popular alternative in medical education and literature is replete with its many benefits; like its ability to foster early acquisition of cognitive skills and encourage deep learning in students (Coles, 1985; Newble and Clarke, 1986; Solomon, 1994; Hmelo-Silver, 1998). It is also found to be beneficial in increasing the level of motivation by helping to develop self directed learning skills that last for whole careers and increasing intrinsic interest in the subject of study (Norman and Schmidt, 1992; Albanese and Mitchell, 1993; Pereira et al, 1993; McGregor et al, 1995; Morrison, 2004). Other authors however, are either in total dissent about the benefits of PBL or offer a suggestion of a need for caution and necessity of further evidence to prove that the benefits are of significance compared to the cost in time, material and effort (Prince, 2004; Colliver and Markwell, 2007). In spite of this, PBL has been advocated for physiotherapy education and is already being used for physiotherapy undergraduate education (Solomon, 1994; Williams et al, 2003).

PBL is an instructional method in which students learn through facilitated problem solving (Hmelo-Silver 2004). In physiotherapy, scientific knowledge is applied in the care of ailments. Therefore, a good acumen at problem solving is of advantage at arriving at correct diagnosis (Saarinen-Rahiika and Binkley, 1998). PBL involves case or problem based activity where enquiry is directed at finding explanations to presented real or imagined lifelike scenarios. The use of PBL in the teaching of physiotherapy students is not new (Saarinen-Rahiika and Binkley, 1998). The impression however is that introduction of changes and modification in rnedical curricula worldwide did not rub on Nigerian medical schools (Ibrahim, 2007). Therefore, in keeping with positive innovation and the trend towards increasing inclination to the PBL approach (Edens, 2000), and also in the belief that PBL will be of advantage to physiotherapy students, the Department of Anatomy in the College of Medicine of the University of 
Lagos introduced the PBL approach in its mode of teaching of Physiotherapy students in their basic medical science year. The need to evaluate the programme as it concerns physiotherapy students has been recognized since the results of a feedback from medical students cannot be extrapolated as applicable to physiotherapy students. This is because there may be differences in the perceptions of the program between different groups of students (Dahlgren and Dahlgren, 2002).

\section{MATERIALSAND METHODS GROUPOFSTUDENTS}

The group of students assayed in this study are second year Physiotherapy students admitted for a fiveyear program leading to the award of a B. Physiotherapy degree. The students had either undergone an intensive one year preliminary programme at the Faculty of Science of the University of Lagos and have passed the requisite pure science based examinations or have been admitted as direct entry students through the meeting of the prescribed scores in General Certificate of advanced level examination or by being holders of a good relevant first degree from recognized institutions.

There were 41 students in this group and there is a good gender balance. They had gone through the Department of Anatomy's PBL programme for nine continuous months covering all body regions. They were also involved academically with other Basic science Departments in the school who do not use the PBL approach.

\section{QUESTIONNAIRE}

A structured questionnaire was used for this study. It had an introductory part that informed prospective respondents of the aims and objectives of the study and solicited their frank and truthful responses. It also promised anonymity and gave simple instruction of the need to mark the options that was nearest to their degree of agreement/disagreement to simple stem statement with sentence completions. There were six options; Strongly agree, Agree, Undecided, Disagree, Strongly disagree and No response.

\section{PBL PROGRAMME.}

As in other PBL programmes, the main feature is to induce the students into individual and group work in arriving at answers or understanding of the basic Anatomy needed to understand. This will enable them to effectively impact professionally on simulated (usually authored by the department) common medical scenarios. The printed scenarios were circulated on Wednesday mornings and the group PBL discussion took place on the following Friday mornings. The class was randomly divided into 4 groups of about 10 students each. Each group had a lecturer from the department as a facilitator that moderated and if need be guide the discussion. Students were encouraged to contribute freely, engage one another's ideas and ask their own questions, the only limitation being time, which was 3 hours.

Sessions took place simultaneously for all 4 groups in the dissection hall that is compartmentalized into different bays; so, each group had an appreciable measure of privacy and isolation. The materials available to the students for research were the Departmental and College libraries, Departmental museum, widely available World Wide Web connections and personal texts and notes.

Facilitators are lecturers in the department, majority of who are new to, but enthusiastic about PBL: At the onset of the programme there was an official "training the facilitators" session by the professor and head of department. Full academic meetings were called to decide and author PBL scenarios, the posers and questions and to emphasize the need to facilitate and not resort to lecture during PBL sessions. Challenges and possible solutions were discussed during these weekly meetings. This way, half of the Anatomy academic programme was covered through PBL while the remaining half was covered by the traditional lectures style.

\section{SURVEYPROCEDURE}

The questionnaires were distributed to willing students at the end of the year- long program a few days before the final examination directly by the authors. Just before the distribution, some members of the study team addressed the class briefly to solicit the students interest and encourage the judicious and correct filling of the questionnaires by letting it approximate as much as possible their honest opinions as the result was intended to further develop the program and for scientific publication. Again anonymity was promised and aptly demonstrated by asking participants to drop completed forms in drop boxes placed at class exits or to be dropped off at a later time. No incentives or rewards were promised or given to respondents. Respondents were encouraged not to leave any question unanswered, but to mark 'no response' instead if they could not make up their minds.

\section{PROCESSING OF THE QUESTIONNAIRE}

The information contained in the completed and returned questionnaires were entered manually into an Ms excel workbook (Microsoft office 2003) designed by the authors for the purpose. The variables were represented by numbers and the "count if" function of the program used to collate. After sorting using the same software, the collated figures were subjected to statistical analysis using chi square analysis also done by the same programme.

\section{RESULTS}

Thirty-five students participated in the survey out of a total of forty one given a percentage response of eighty five percent. The collated responses in percentages are given below in Tables $1-6$. 
Problem Based Learning in Basic Medical science training for 200 level Physiotherapy students -AI Aiyegbusi et al

Table 1: Responses (\%) to the Sentence Completion Questions Designed to Survey Respondents views about cases/problems used for $\mathrm{pbl}$, prefixed by ' $\mathrm{i}$ find the $\mathrm{pbl}$ cases/problems"

\begin{tabular}{|c|c|c|c|c|c|c|}
\hline \multirow{2}{*}{$\begin{array}{l}\text { Strongly agree } \\
\text { Too advanced }\end{array}$} & \multirow{2}{*}{$\begin{array}{l}\text { Agree } \\
8.7\end{array}$} & \multicolumn{2}{|c|}{ Undecided } & \multirow{2}{*}{$\begin{array}{l}\text { Disagree } \\
48.7\end{array}$} & \multirow{2}{*}{$\begin{array}{l}\text { Strongly } \\
\text { disagree }\end{array}$} & \multirow{2}{*}{$\begin{array}{l}\text { No } \\
\text { response } \\
0\end{array}$} \\
\hline & & 8.7 & 15.4 & & & \\
\hline Too elementary & 6 & 2.7 & 12.6 & 32.8 & 45.9 & 0 \\
\hline Relevant to basic anatomy & 63.9 & 24.4 & 0 & 4 & 7.7 & 0 \\
\hline Not relevant to basic anatomy & 9 & 2.8 & 0 & 32.9 & 55.3 & 0 \\
\hline Cover the topics intended & 45.3 & 27.7 & 0 & 17.3 & 9.7 & 0 \\
\hline $\begin{array}{l}\text { Don't cover the topics } \\
\text { intended }\end{array}$ & 14.5 & 17.3 & 7.9 & 24.3 & 35.8 & 0 \\
\hline
\end{tabular}

Table 2: Percentage Responses to the Sentence Completion Questions designed to Survey Respondents Attitude towards the pbl Programme and Activities, prefixed by 'since the commencement of $\mathrm{pbl}$ i find $\mathrm{i}$-,

\begin{tabular}{lllllll} 
& SA & A & U & D & SD & NR \\
\hline "Am Eager to Attend & 46.7 & 23.3 & 13 & 10 & 6.7 & 0 \\
"Prefer Sessions to Lectures & 26.1 & 26.1 & 16 & 9 & 22.8 & 0 \\
"Gain more in Pbl Sessions than Lectures" & 32.4 & 19.1 & 16 & 16 & 16 & 0 \\
"Personally Rsearch before Sessions" & 36.7 & 16.7 & 20 & 17 & 10 & 0 \\
"Prefer Group to Personal Research" & 35.4 & 25.7 & 16 & 6.5 & 16.2 & 0 \\
"Participate during Sessions" & 40 & 26.7 & 17 & 6.7 & 10 & 0 \\
"Don't Participate during Sessions" & 6.7 & 10 & 13 & 17 & 53.3 & 0 \\
\hline
\end{tabular}

KEY: SA; Strongly Agree, A; Agree, U; Undecided, D; Disagree, SD; Strongly Disagree, NR; No Response

Table 3: Percentage Responses to the sentence completion questions designed to Survey Respondents Impression of Personal Positive Impact of PBI Prefixed by 'since the commencement of PBI Find .

\begin{tabular}{lllllll}
\hline & SA & A & U & D & SD & NR \\
\hline "My Knowledge Base Has Improved" & 65.4 & 16.2 & 5.7 & 5.6 & 7.1 & 0 \\
"I am better at Material Search" & 45.8 & 21.7 & 24.8 & 3.8 & 3.9 & 0 \\
"I am better at Problem Solving" & 37.9 & 31 & 13.8 & 10.3 & 6.9 & 0 \\
"I Study More" & 44.1 & 34.2 & 12.9 & 2.9 & 5.9 & 0 \\
"I Interact better with Mates" & 48.3 & 20.7 & 17.2 & 6.9 & 6.9 & 0 \\
Pbl Activity helpful in Theory Exams & 77.3 & 12.8 & 6.7 & 0 & 3.2 & 0 \\
Pbl Activity helpful in Practical Exams & 65.5 & 24.1 & 6.9 & 3.4 & 0 & 0 \\
"I am more Eager for Clinical School." & 76.9 & 18.2 & 0 & 4.9 & 0 & 0 \\
"My Confidence Level Increased" & 56.2 & 25.1 & 7.9 & 0 & 10.8 & 0 \\
\hline
\end{tabular}

Table 4: Responses (\%) to the Sentences Competions Designed to Asses Opinions of Respondents, Prefixed By 'In My Opinion I-

\begin{tabular}{lllllll}
\hline & SA & A & U & D & SD & NR \\
\hline Recommend we have more of Pbl & 63.3 & 23.3 & 10 & 0 & 3.3 & 0 \\
Recommend we have less of Pbl & 6.7 & 3.3 & 13.3 & 23.3 & 53.3 & 0 \\
Recom more of Lectures than Pbl & 20 & 10 & 16.7 & 30 & 23.3 & 0 \\
Recommend we Stop Pbl Entirely & 3.3 & 3.3 & 6.7 & 13.3 & 73.3 & 0 \\
Think Pbl not Suited for Anatomy & 0 & 4.1 & 4.3 & 4.8 & 86.7 & 0 \\
Think Pbl Not Suited for Any Basic & 11 & 0 & 4.3 & 11 & 73.7 & 0 \\
Medical Science & & & & & & \\
\hline
\end{tabular}

KEY: SA; Strongly Agree, A; Agree, U; Undecided, D; Disagree, SD; Strongly Disagree, NR; No Response 
Problem Based Learning in Basic Medical science training for 200 level Plyysiotherapy students -AI Aiyegbusi et al

Table 5: responses $(\%)$ to the sentences completions questions designed to test motivation for participating during $\mathrm{pbl}$ sessions, prefixed by 'when i find myself actively participating during $\mathrm{pbl}$ sessions, usually, it is due to the -

\begin{tabular}{|c|c|c|c|c|c|c|}
\hline & $\mathbf{S a}$ & $\overline{\mathbf{A}}$ & $\overline{\mathbf{U}}$ & $\mathbf{D}$ & Sd & $\overline{\mathbf{N}} \mathbf{r}$ \\
\hline Desire to make others benefit & 42.8 & 14.6 & 10.7 & 10.8 & 21.1 & 0 \\
\hline Need to test my knowledge & 64.4 & 19.6 & 13.1 & 0 & 2.8 & 0 \\
\hline Compulsion & 23.8 & 4.9 & 8.4 & 16 & 46.8 & 0 \\
\hline Peer pressure & 3.9 & 14.7 & 10.8 & 10.7 & 59.9 & 0 \\
\hline Love for $\mathrm{pbl}$ & 37.2 & 23.4 & 16.5 & 13.2 & 9.7 & 0 \\
\hline
\end{tabular}

KEY: SA; Strongly Agree, A; Agree, U; Undecided, D; Disagree, SD; Strongly Disagree, NR; No Response

Table 6: Responses (\%) to the Sentences Completions Prefixed by 'when i find myself not actively participating during pbl sessions, "usually, it is due to -"

\begin{tabular}{lllllll} 
& Sa & $\mathbf{A}$ & $\mathbf{U}$ & $\mathbf{D}$ & $\mathbf{S d}$ & $\mathbf{N r}$ \\
\hline Timidity & 21.3 & 7.5 & 17.8 & 7.5 & 46 & 0 \\
Peer pressure & 7.5 & 0 & 22.4 & 14.8 & 55.3 & 0 \\
Lack of knowledge & 12.3 & 4.6 & 7.5 & 15.9 & 59.7 & 0 \\
Dislike for session & 11.2 & 0 & 11.2 & 3.7 & 73.9 & 0 \\
Communication handicap & 19.7 & 3.7 & 3.7 & 12.6 & 60.2 & 0 \\
\hline
\end{tabular}

KEY: SA; Strongly Agree, A; Agree, U; Undecided, D; Disagree, SD; Strongly Disagree, NR; No Response

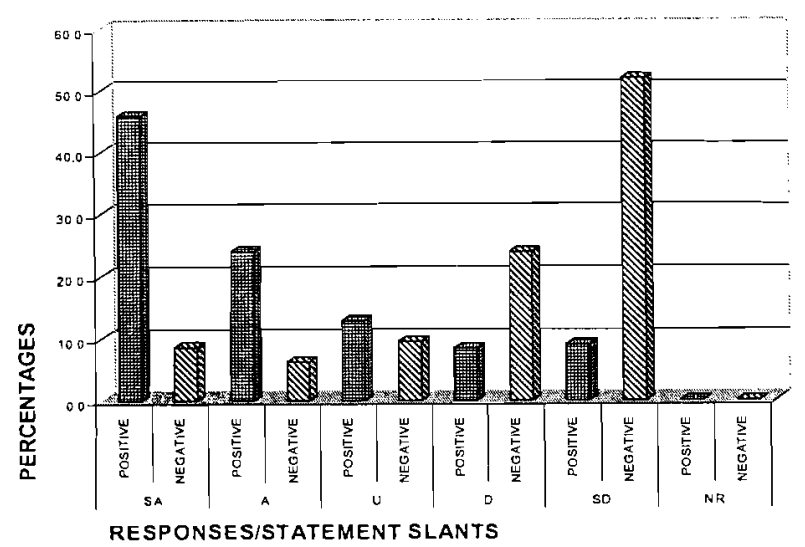

Figure 1: Agreggate Responses to Positive and Negative Statements.

*Significant at $\mathrm{p}<0.1$

KEY: SA; Strongly Agree, A; Agree, U; Undecided, D; Disagree, SD; Strongly Disagree, NR; No Response

\section{DISCUSSION}

In this survey, the response rate is eighty five percent, which appears adequately sufficient for the result of this survey to be construed as aggregating the group's opinion about the subject matter (Parashos et al, 2005). Non response bias issues were therefore not put into cognizance in this report (Asch et al, 1997.

Figure 1 indicates the tilt of the class' opinion to an oversimplified question that summarizes the responses to a like/dislike, good/bad and want/don't want level. To arrive at this extrapolation, thirteen sentence completion question/ statements which aggregate 'like/good/want' and eleven questions that connotes 'dislike/bad/don't want' were gathered. The exercise suggests that at the simplest level of 'good/bad' the students favored 'good'. Of note however is that the percentage that disagreed $(75.7 \%)$ with negative connotation question /statement completions is more than the percentage that agreed $(69.7 \%)$ with positive connotation sentence completions. Furthermore, a paired student's t-test at $p<0.1$ of the arrived figures was statistically significant. It therefore appears that this group of students polled favorably towards PBL, but more so because it is not such a 'bad' thing than that it is actually a 'good' thing.

In Table 1 the result to the sentence completion questions designed to survey respondents' views about cases/problems used for PBL is presented. The result shows that $79 \%$ percent agree that the cases/problems used are relevant and $73 \%$ at least agreeing that they cover topics intended for the PBL sessions. In PBL the quality, relevance and general adequacy of the cases/problems used to direct learning and teaching of intended topics are pivotal (Keppell, 2005; Vanleit and Cubra, 2005). In the first year and with the pioneer set of the PBL programme, it is encouraging to note that this important aspect of the programme has met the students' expectation.

A good attitude towards the PBL programme and the activities involved is shown in Table 2. This is to be expected as the aggregate opinion of opinions suggests a likeness for the programme. It can be posited based on this that the acclaimed benefit of PBL is not lost in this group of students even as they are the first group to go through the programme in a Department introducing PBL for the first time (Norman and Schmidt, 1992; Albanese and Mitchell 1993, Vernon and Blake, 1993; Morrison, 
2004) It is this impact of PBL that the survey items reported in Table 3 are designed to assess. There is a general opinion in the impression of the students that the developing program affords these benefits even in its evolution. The survey report also indicates a student impression of augmentation of knowledge, which is in consonance with views elsewhere as reported (Prince et al, 2003). Expectedly, the opinions of the students favor an increase in the proportion of $\mathrm{PBL}$ activities as $63.3 \%$ of respondents would like an increase in time allotted for PBL and over half (53.3\%) at least disagreed with the suggestion of more didactic lectures than PBL (Table 4).

From Table 5 it is seen that the factor that drives this group of student most to participate is the quest for and need to acquire knowledge. PBL provides a good platform for this as a result of interaction with fellow students and facilitators. On its own, the position of drive for knowledge is a good argument in favor of PBL as it is not ideal for students to wait for the examination to test the knowledge acquired. Exhibition and trial of knowledge is facilitated during PBL group discussions (Schmidt et al ,2006). Timidity which is identifiable in this survey as the greatest factor that contributes to non- participation (Table 6) would militate against maximizing the opportunities available with PBL. This is instructive as it highlights the need for facilitators widen their reach and increase the level of engagement with the students.

\section{CONCLUSION}

PBL programme can be beneficial to pioneer physiotherapy students in basic medical science year even when a department that is still developing in the progran administers it newiy.

\section{REFERENCES}

- Albanese MA, Mitchell S(1993). Problem-Based Learning: A Review of Literature on its Outcomes and Implementation Issues. Acad Med. 68:52-81.

- Asch DA, Jedrziewski MK, Christakis NA. (1997). Response rates to mail surveys published in medical journals $J$ Clin Epidemiol. 50(10): $1129-36$

- Coles CR. (1985). Differences between conventional and problem-based curricula in their students' approaches to studying. Medical Education; 19: 308-309.

- Colliver JA, Markwell SJ. (2007) Research on problenbased learning: the need for critical analysis of methods and findings. Medical Education 41 (6): 533-535

- Dahlgren MA and Dahlgren LO.(2002). Portraits of PBL: students' experiences of the characteristics of problem-based learning in physiotherapy, computer engineering and psychology. Instructional Science. 30(2): 111-127

- Edens, K. (2000). Preparing problem solvers for the 21 st Century through Problem Based Learning. College Teaching, 48(2): $55-60$.

- Hmelo-Silver CE. (1998) Problem-Based Leaning: Effects on the Early Acquisition of Cognitive Skill in Medicine The Joumal of the Learning Sciences. 7(2): 173-208
- Hmelo-Silver CE. (2004). Problem-Based Learning: What and How Do Students Learn? Educational Psychology Review. 16(3): 235- 236

- Ibrahim M. (2007). Medical education in Nigeria : Medical Teacher 29(9\&10): $901-905$

- Keppell, M. (2005). Reusable media-rich problem-based leaming cases: Creating leaming objects for teacher-education. In P. Kommers \& G. Richards (Eds.), Proceedings of World Conference on Educational Multimedia, Hypermedia and Telecommunications 2005 (pp. 1865-1873). Chesapeake, VA: AACE.

- McGregor DB, Arcomano TR, Bjerke HS, Little AG. (1995). Problem orientation is a new approach to surgical education. The American Journal of Surgery 170: 656-659.

- Morrison J. (2004). Where Now for Problem-Based Learning? The Lancet 363:174-174.

- Newble DI, Clarke RM. (1986). The approaches to learning of students in a traditional and in an innovative problembased medical school. Academic Medicine. 67: 557-565.

- Norman, G. R. and Schmidt, H. G. (1992). The psychological basis of problem-based learning: a review of the evidence. Academic Medicine. 67: 557-565

- Norman, GR. and Schmid, HG. (1992). The psychological basis of problem-based learning: a rcview of the evidencc. Academic Medicine. 67:557-565

- Parashos P, Morgan MV, Messer HH. (2005) Response rate and non response bias in a questionnaire survey of dentists Community Dentistry and Oral Epidemiology 33(1): 9-16

- Pereira LMP, Telang BV, Butler KA. (1993). Preliminary evaluation of a new curriculum - incorporation of Problem Based Learning (PBL) into the traditional format. Medical Teacher. 15(4): 351-364.

(2) Prince M. (2004). Does Active Learning Work? A Review of the Research. J. Engr. Education. 93 (3): 223 - 231.

- Prince KJA, van Mameren $\mathrm{H}$, Hylkema $\mathrm{H}$, Jan Drukker, Albert J A Scherpbier, Cees P M van der Vleuten (2003) Does problem-based learning lead to defieiencies in basic science knowledge? An empirical case on anatomy. Medical Education 37(1): 15-21.

Saarinen-Rahiika H and Binkley JM. (1998). Problem-based learning in physical therapy: a review of the literature and overview of the McMaster University experience. Phys Ther: 78(2): 195-207

- - Schmidt HK; Loyens SMM, Van Gog T, Paas F (2006). Problem-Based Learning is Compatible with Human Cognitive Architecture: Commentary on Kirschner, Sweller, and Clark. Educational Psychologist. 42(2): 91 - 97.

6) Solomon P (1994) Problem-based lcarning: A direction for physical therapy education? Physiotherapy Theory and Practice. 10(1): 45 - 52

- 6 Vanleit B, Cubra J. (2005). Student-developed problembased learning cases: preparing for rural healthcare practice. Rural Remote Health. 5(4): 399.

- Vernon, D T. and Blake RL. (1993). Does problem-based learning work? A meta-analysis of evaluative research. Academic Medicine. 68: 550-563.

- Williams R, MacDermid J, Wessel J. (2003). Student adaptation to problen-based learning in an entry-level master's physical therapy program Physiotherapy Theory and Practice. 19(4): $199-212$ 